\title{
PREDICTION OF ACID, PEROXIDE AND TBA VALUES OF HEAT-TREATED PALM OIL USING A PARTIAL LEAST SQUARES-ORDINARY LEAST SQUARES MODEL BASED ON FOURIER TRANSFORM INFRARED SPECTROSCOPY
}

\author{
KUSNANDAR, F $^{1 *}$; LIOE, H N¹; FARIDAH, D N'; ANGGRAENI, ${ }^{1}$ and PRICILIA ${ }^{1}$
}

\begin{abstract}
Palm oil is widely used for frying food and is often used for repeated frying up to $40 \mathrm{hr}$ or even longer. Frying causes a gradual quality decrease during heating due to fat oxidation or hydrolysis. The quality of fats and oils is commonly monitored by acid, peroxide and thiobarbituric acid values ( $A V, P V$ and $T B A V$, respectively). This study aimed to use a partial least squares-ordinary least squares (PLS-OLS) model obtained from Fourier transform infrared (FTIR) spectroscopy to predict $A V, P V$ and TBAV values of heat-treated palm oil. Commercial palm oil was heated at $180^{\circ} \mathrm{C}$ for $72 \mathrm{hr}$. The multivariate mathematical models to predict $A V, P V$ and TBAV were generated from the percentages of absorbance intensity of significant wavenumbers based on FTIR readings (721.4, 871.8, 968.3, 1033.9, 1095.6, 1377.2, 1462, 1751.4, 2731.2, 2839.2 and $\left.3005.1 \mathrm{~cm}^{-1}\right)$. The PLS-OLS mathematical model satisfactorily predicted both $A V$ and $P V$ for palm oil samples heated up to $72 \mathrm{hr}\left(R^{2}=0.962\right.$ and 0.857 , respectively), whereas for $T B A V$, the time was $58 \mathrm{hr}\left(R^{2}=0.845\right)$. This approach provides an alternative to monitoring palm oil quality during frying instead of the conventional methods in which the analytical procedures are time-consuming.
\end{abstract}

\section{Keywords: fat oxidation, FTIR spectroscopy, heat stability, ordinary least square, palm oil.}

Received: 15 December 2019; Accepted: 6 September 2020; Published online: 30 November 2020.

\section{INTRODUCTION}

The quality of oil gradually decreases due to fat oxidation and fat hydrolysis, which is proportional to frying time and/or frying cycles (Bhuiyan et al., 2016; Jaarin and Kamisah, 2012). Fat oxidation involves the reaction between the unsaturated carbon bonds of fatty acids and oxygen, resulting in the formation of unstable hydroperoxide as a primary product (Dana and Saguy, 2001; Gharby et al., 2014). Moreover, the hydroperoxide undergoes rapid degradation into stable aldehydes

Department of Food Science and Technology,

Bogor Agricultural University (IPB University),

Dramaga Campus, Bogor 16680, Indonesia.

* Corresponding author e-mail: fkusnandar@apps.ipb.ac.id as secondary products, which are responsible for rancid odour (Frankel, 1987). Peroxide and thiobarbituric acid values (PV and TBAV, respectively) for indicating hydroperoxide and aldehyde formations, respectively, can describe the extension of oxidation. Additionally, the duration, method of frying, type of frying medium and characteristics of the fried product may influence the degree of rancidity (Bhuiyan et al., 2016).

Palm oil is commonly used as a heating medium for deep-fat frying in households, fast-food outlets, and restaurants with specific frying times of $12-40 \mathrm{hr}$ and a temperature at least of $180^{\circ} \mathrm{C}$ (Bhuiyan et al., 2016; Faridah et al., 2015). Palm oil is susceptible to oxidation when it is used for frying under such conditions as it mainly consists of monounsaturated 
fatty acids, such as oleic acid (C18:1) at 39.2\% and polyunsaturated fatty acids, such as linoleic acid (C18:2) and linolenic acid (C18:3) at 10.5\% (Mancini et al., 2018). Additionally, hydrolysis, which is a splitting reaction of triglycerides into free fatty acids (FFA) and glycerol (Frankel, 1987), is also a cause of palm oil deterioration. The presence of short-chain FFA, expressed as acid value (AV), also contributes to the formation of rancid odour.

The monitoring of palm-based cooking oil during frying commonly focuses on the quantitative values of AV, PV and TBAV (Kalapathy and Proctor, 2000; Setiowaty and Che Man, 2003). However, the procedures involved (for example, sample preparation and titration) in determining these parameters are sometimes tedious. Therefore, an alternative method that may be substantial in cutting down the analytical times for measuring $\mathrm{AV}, \mathrm{PV}$ and TBAV is needed and should be investigated.

Nowadays, Fourier transform infrared (FTIR) spectroscopy is widely used to analyse the quality of edible oils. The principle of FTIR is to measure the infrared spectrum of absorption over a range of wavenumbers. The identification of functional groups or bonds are possible by reading significant absorbance intensity at certain wavelengths. In this study, similar to the fingerprint method for identifying chemical substances, FTIR is considerably powerful, rapid, simple and relatively cost effective. Recent studies have shown that FTIR is capable of identifying the adulterated compounds in palm oil and reheated palm oil (Che Man et al., 2014; Lim et al., 2018; Faridah et al., 2015), determining purity of olive oil and crude oil (Rohman and Che Man, 2010; Abdulkadir et al., 2016) and authentify avocado oil (Rohman et al., 2015). Moreover, Ang et al. (2019) and Wong et al. (2019) have reported the rapid quantification of processing contaminants [such as 3-mono-chloropropane-1,2-diol (MCPD) esters] in palm-based cooking oil using FTIR spectroscopy.

FTIR spectroscopy cannot be used to directly measure the intensity of oil deterioration. However, the results of FTIR analysis can correlate with the oil's quality parameters. For establishing this correlation, the partial least squares (PLS) in combination with an ordinary least squares (OLS) method may be used. PLS is a multivariate and covariance-based statistical method that compares the multiple response and explanatory variables (Höskuldsson, 1998) and thus, satisfactorily predicts ' $y$ ' from ' $x$ ' (Abdi, 2003). As a part of PLS, the OLS regression generates a mathematical model between the sample's data points and the predicted values (Farahani et al., 2010). Therefore, the use of PLS-OLS is a powerful method for interpreting collinear data from FTIR measurements (Li, 2010). The use of the PLS-OLS regression model for the interpretation of FTIR measurements in palm oil during frying has been reported (Faridah et al., 2015; Setiawaty and Che Man, 2003; Rohman and Che Man, 2010; Martín-Ramos et al., 2018).

One of the reported advantages of PLS-OLS is the simplicity of the method when monitoring oil quality (Faridah et al., 2015). On that note, it is a need to investigate such an alternative method that may be substantial in cutting down the analytical times for measuring AV, PV and TBAV exists. Hence, within this study, the use of a PLS-OLS mathematical model to correlate the FTIR measurements with AV, PV and TBAV of heated palm oil was demonstrated and verified.

\section{MATERIALS AND METHODS}

\section{Materials}

A commercial palm oil from a production batch was purchased from a local market in Bogor, Indonesia. The sample consisted of pure palm oil as mentioned on its label. The chemicals for analysis were potassium hydrogen phthalate (KHP) crystals, phenolphthalein in alcohol (1\%), 96\% technical alcohol, glacial acetic acid, $0.01 \mathrm{~N} \mathrm{Na}_{2} \mathrm{~S}_{2} \mathrm{O}_{3}$ solution, $1 \%$ starch solution, saturated potassium iodide (KI) solution and thiobarbituric acid (TBA) reagent. All chemical reagents used were of analytical grade.

\section{Sample Preparation and Analysis}

Ten litres of cooking oil was heated using a controlled-temperature deep fat fryer (Getra model EF-88) at $180^{\circ} \mathrm{C}$ for up to $72 \mathrm{hr}$. The selected heating temperature and time were in accordance to Setiowaty and Che Man (2003). Samples were withdrawn every $2 \mathrm{hr}$, placed in dark glass bottles (with a capacity of $30-50 \mathrm{ml}$ ), and stored at a $3{ }^{\circ} \mathrm{C}$ for further analyses. A non-heated sample was also prepared as a control. Samples were prepared in duplicate; hence, 74 samples were obtained.

\section{AV Analysis}

The determination of $\mathrm{AV}$ followed AOAC 940.28 (AOAC, 1984). The sample (2.5 g) was dissolved with $50 \mathrm{ml}$ 96\% alcohol in an Erlenmeyer flask. After a short period of heating on a hot plate, the sample was titrated using $0.01 \mathrm{M} \mathrm{NaOH}$ solution. The AV was calculated according to the Equation (1):

$$
\mathrm{AV}\left(\mathrm{mg} \mathrm{NaOH} \mathrm{g}^{-1} \text { sample }\right)=\mathrm{V}_{\mathrm{NaOH}} \times \mathrm{M}_{\mathrm{NaOH}} \times \mathrm{n}_{\mathrm{NaOH}}
$$

in which $\mathrm{V}=$ volume $(\mathrm{L}), \mathrm{M}=$ molarity $(\mathrm{M})$ and $\mathrm{n}=\mathrm{mol}$. The molecular weight of $\mathrm{NaOH}$ is $40 \mathrm{~g} \mathrm{~mol}^{-1}$. 


\section{PV Analysis}

The PV analysis was determined according to a national standard method (SNI, 1998). Samples (0.25 g) were added to the mixture of $30 \mathrm{ml}$ of glacial acetic acid solution and chloroform (3:2), $3 \mathrm{ml}$ saturated potassium iodide, $30 \mathrm{ml}$ of distilled water and $1 \mathrm{ml}$ indicator (1\% starch solution). After thoroughly agitating for $3 \mathrm{~min}$, the sample was titrated with $0.01 \mathrm{~N}$ standard solution of sodium thiosulphate. PV was calculated with the Equation (2):

$\mathrm{PV}\left(\right.$ meq peroxide $\mathrm{kg}^{-1}$ sample $)=(\mathrm{Vs}-\mathrm{Vb}) \times \mathrm{N} \times 1000 / \mathrm{W}$

in which $\mathrm{Vs}=$ volume of titration for sample (L), $\mathrm{Vb}=$ volume of titration for blank sample $(\mathrm{L}), \mathrm{N}$ $=$ normality of sodium thiosulphate solution $(\mathrm{N}=$ $0.01)$ and $\mathrm{W}=$ sample weight $(\mathrm{g})$.

\section{TBAV Analysis}

The TBAV analysis followed the method of Tarladgis et al. (1962). Sample (10 g) was mixed with $2.5 \mathrm{ml}$ of $4 \mathrm{M} \mathrm{HCl}$ to reach a $\mathrm{pH}$ of 1.5 and then diluted to a total volume of $100 \mathrm{ml}$ with distilled water. The sample was then distilled to obtain $50 \mathrm{ml}$ distillate. After stirring evenly, $5 \mathrm{ml}$ of distilate was pipetted into a closed test tube and then $5 \mathrm{ml}$ of TBA reagent $\left(0.2883 \mathrm{~g}\right.$ TBA $100 \mathrm{ml}^{-1}$ of $90 \%$ glacial acetic acid) was added into the solution. After thorough mixing, the mixture was heated in a boiling water bath for $35 \mathrm{~min}$ until a red colour solution was obtained. The sample was immediately cooled, and the absorbance was monitored at $538 \mathrm{~nm}$ using a Genesys 10S UV-Vis spectrophotometer (Thermo Scientific, USA). The TBAV was calculated using the Equation (3):

$$
\begin{gathered}
\text { TBAV } \\
\underset{\left.\mathrm{kg}^{-1} \text { sample }\right)}{\text { mg malondialdehyde }}= \\
\left(\begin{array}{c}
\text { Absorbance } \times 7.8 \\
\left.\mathrm{~g}^{-1} \text { sample }\right)
\end{array} .10\right.
\end{gathered}
$$

\section{FTIR Spectrum Analysis}

The procedure for FTIR spectroscopy analysis referred to Faridah et al. (2015). FTIR spectroscopy (IR-Prestige 21 model, Shimadzu Corporation, Japan) identified major wavenumbers that indicates significant absorbance intensity. The potassium bromide $(\mathrm{KBr})$ plate was previously cleaned, wiped with analytical grade $n$-hexane and then dried with lens tissue for each sample measurement. The oil sample was then dropped onto the $\mathrm{KBr}$ plate and covered with another $\mathrm{KBr}$ plate to form a sandwich plate. The absorbance was read in duplicate at wavenumbers of $400-4000 \mathrm{~cm}^{-1}$ at a resolution of 1.9. The wavenumbers with the significant reading of absorbance intensity were used to predict functional groups or bonds by referring to relevant published FTIR analysis. The relative percentage of an absorbance intensity (to the sum of all absorbance intensities of significant wavenumbers) was calculated for each significant wavenumber of FTIR reading. This value was used for multivariate analysis.

\section{PLS-OLS Multivariate Analysis}

The data of absorbance intensity selected from a significant wavenumber of an FTIR spectroscopy reading was previously converted to a percentage of absorbance intensity (\%IA) according to the Equation (4) (Faridah et al., 2015):

$$
\% \mathrm{IAx}=\frac{I A x}{I A \text { total }}
$$

in which:

$\% \mathrm{IAx}=$ percentage of absorbance intensity at sigificant wavenumbers

IAx = absorbance intensity at significant wavenumbers

IA total $=$ total of absorbance intensity

The software of XLSTAT version 2013 (Microsoft Excel Series) was used to perform a PLS-OLS multivariate analysis. The multivariate mathematical models were generated to correlate the percentage of absorbance intensity (\%IA) of selected wavenumbers at $X$ axis with $A V, P V$, or TBAV at $Y$ axis. The coefficient of determination $\left(R^{2}\right)$ was used as the validity criteria for PLS-OLS mathematical model.

\section{Verification}

Verification was performed to ensure the validity of the generated mathematical models to predict AV, PV and TBAV. A cooking oil sample was heated at $180^{\circ} \mathrm{C}$ for $24 \mathrm{hr}$ and analysed in terms of FTIR profile, $\mathrm{AV}, \mathrm{PV}$ and TBAV were evaluated by applying the same methods described above. A paired $t$ statistical analysis was performed to observe the degree of deviation between actual and predicted $\mathrm{AV}, \mathrm{PV}$ or TBAV values.

\section{RESULTS AND DISCUSSION}

\section{Spectrum Profile and Absorbance Intensity}

Figure 1 depicts the absorbance intensity of palm oil samples for control and those heated at $180^{\circ} \mathrm{C}$ for up to $72 \mathrm{hr}$ measured at wavenumbers of 400-4000 $\mathrm{cm}^{-1}$. This wavenumber range was accessible with the use of $\mathrm{KBr}$ and has also been 
used in previous studies (Faridah et al., 2015; Vlachos et al., 2006; Al-Degs et al., 2011). The figure indicates a similar absorbance intensity profile between control samples and those heated at $180^{\circ} \mathrm{C}$ for $72 \mathrm{hr}$. A similar absorbance intensity profile was also shown at other heating times (data are not presented). The data indicate that the absorbance intensity from FTIR readings did not differ among tested samples.

Figure 1 shows 11 wavenumbers with significant absorbance intensities, for examples, 721.4, 871.8, 968.3, 1033.9, 1095.6, 1377.2, 1462, 1751.4, 2731.2, 2839.2 and $3005.1 \mathrm{~cm}^{-1}$. Referring to the previous studies (Faridah et al., 2015; Vlachos et al., 2006; AlDegs et al., 2011), these wavenumbers indicate the presence of specific functional groups (Table 1). The wavenumber of $3005.1 \mathrm{~cm}^{-1}$ indicates the existence of alkene group $(C=C)$ as described by Rohman and Che Man (2010) and Che Man and Setiowaty (1999b). This alkene group appears due to the presence of double bond of fatty acids in triglyceride molecules. Palm oil contains considerable amount of unsaturated fatty acids, such as oleic and linoleic acids (Edem, 2002; Mba et al., 2015). The existence of triglycerides in palm oil can be confirmed by the existence of $\mathrm{C}=\mathrm{O}$ group at wavenumbers of 1033.9 $\mathrm{cm}^{-1}$ (Rohman and Che Man, 2010) and 1095.6 $\mathrm{cm}^{-1}, \mathrm{C}=\mathrm{O}$ groups at $1751.4 \mathrm{~cm}^{-1}$ (Rohman and Che Man, 2010; Che Man and Setiowaty, 1999b) and the $\mathrm{CH}_{2}$ and $\mathrm{CH}_{3}$ groups at a wavenumber of $721.4 \mathrm{~cm}^{-1}$ (Che Man and Setiowaty, 1999a), $1377 \mathrm{~cm}^{-1}$ (Rohman and Che Man, 2010), and $1462 \mathrm{~cm}^{-1}$ (Che Man and Setiowaty, 1999b). These groups are the major groups of esterified fatty acids (Berger, 2010). The presence of ester bonds indicates that fatty acid chains are still linked to glycerol moeity leading to the existence of triglycerides. The wavenumber of $871.8 \mathrm{~cm}^{-1}$ indicates the existence of cis $\mathrm{C}=\mathrm{C}$ group (Faridah et al., 2015). This group might originate from the double bonds of fatty acids attached at the triglyceride chain. Significant absorbance was also detected at the wavenumber of $968 \mathrm{~cm}^{-1}$, indicating the existence of a trans $\mathrm{C}=\mathrm{C}$ group (Rohman and Che Man, 2010; Che Man and Setiowaty, 1999b). The presence of this group indicates that palm oil sample contained trans unsaturated fatty acid residues that might been formed during the heating process of palm oil (Song et al., 2015; Bhardwaj et al., 2016). The existence of aldehyde and ester groups as the result of secondary oxidation formation was indicated at a wavenumber of $2731.2 \mathrm{~cm}^{-1}$ (Guillen and Cabo, 1997), 2839.2 $\mathrm{cm}^{-1}$ (Al-Degs et al., 2011), and $1751.4 \mathrm{~cm}^{-1}$ (Rohman and Che Man, 2010). The extensive heat treatment of palm oil caused the formation of unstable peroxide components that were rapidly converted to secondary components, such as aliphatic aldehyde, alcohol, ketone and other hydrocarbons (Wrolstad et al., 2000).

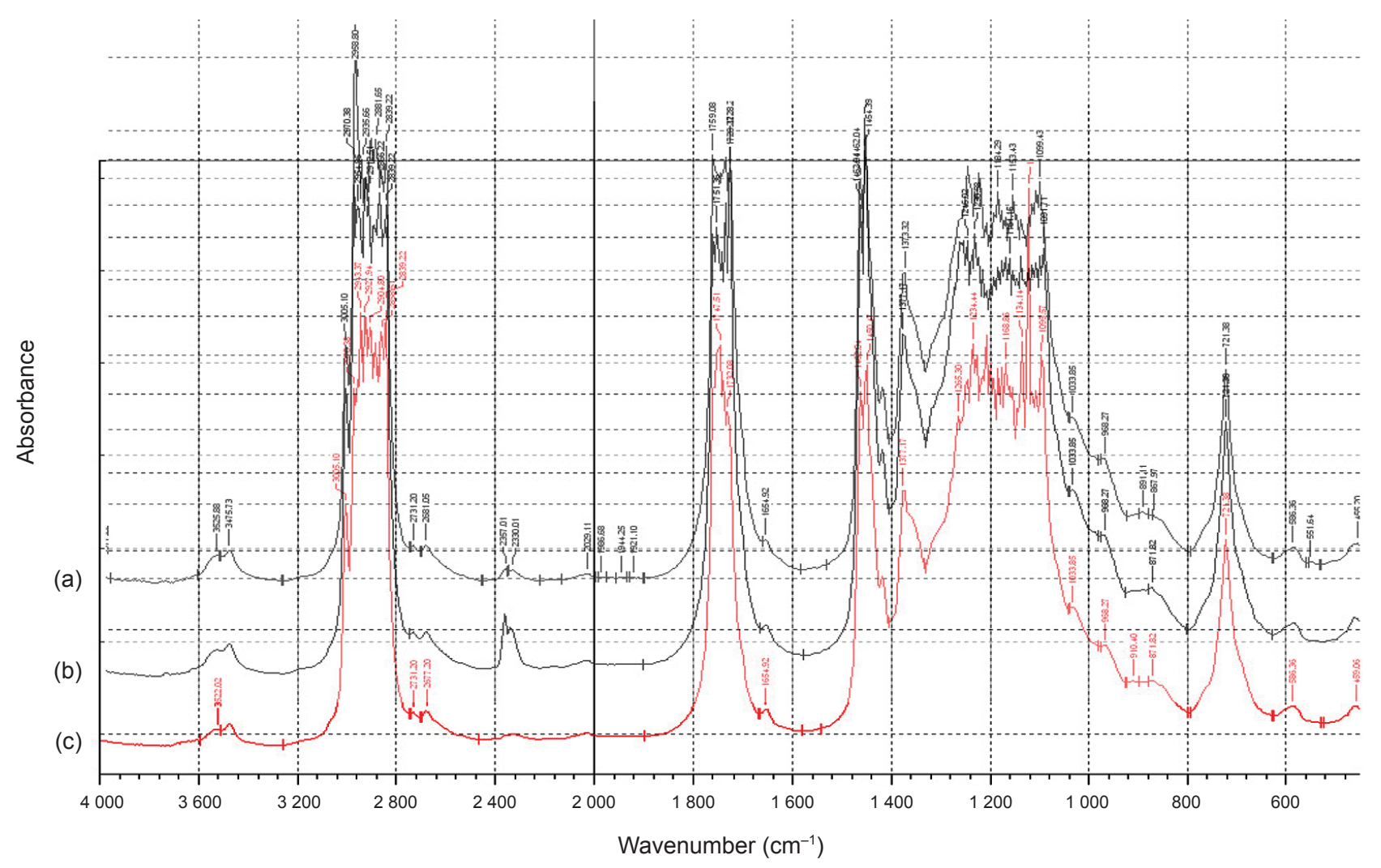

Figure 1. Fourier transform infrared (FTIR) absorbance intensities of (a) palm oil for control, (b) those heated at $180^{\circ} \mathrm{C}$ for $38 \mathrm{hr}$, and (c) $72 \mathrm{hr}$. 
TABLE 1. PREDICTED FUNCTIONAL GROUPS OF PALM OILS BASED ON SIGINIFICANT FOURIER TRANSFORM INFRARED (FTIR) SPECTROSCOPY WAVENUMBERS

\begin{tabular}{|c|c|c|}
\hline Wavenumber $\left(\mathrm{cm}^{-1}\right)$ & Functional groups & References \\
\hline 721.4 & $-\mathrm{CH}_{2}^{-}$ & Che Man and Setiowaty (1999a) \\
\hline 871.8 & Cis $C=C$ & Faridah et al. (2015) \\
\hline 968.3 & Trans $\mathrm{C}=\mathrm{C}$ & $\begin{array}{l}\text { Rohman and Che Man (2010); } \\
\text { Che Man and Setiowaty (1999b) }\end{array}$ \\
\hline 1033.9 & $\mathrm{C}-\mathrm{O}$ & Rohman and Che Man (2010) \\
\hline 1095.6 & $\mathrm{C}-\mathrm{O}$ & Rohman and Che Man (2010) \\
\hline 1377.2 & $-\mathrm{CH}_{3}$ & Rohman and Che Man (2010) \\
\hline 1462.0 & $-\mathrm{CH}_{2}-$ and $-\mathrm{CH}_{3}$ & Che Man and Setiowaty (1999b) \\
\hline 1751.4 & $\mathrm{C}=\mathrm{O}$ & Che Man and Setiowaty (1999b) \\
\hline 2731.2 & $-\mathrm{CHO}$ & Guillen and Chabo (1997) \\
\hline 2839.2 & $-\mathrm{O}-\mathrm{CH}_{3}$ & Al-Degs et al. (2011) \\
\hline 3005.1 & $\mathrm{C}=\mathrm{C}$ & $\begin{array}{l}\text { Rohman and Che Man (2010); } \\
\text { Che Man and Setiowaty (1999b) }\end{array}$ \\
\hline
\end{tabular}

\section{AV, PV and TBAV}

The AV shows the concentration of FFA in fats and oils. A FFA is formed as a result of triglyceride breakage (Wrolstad et al., 2000). Figure 2a shows the AV of cooking oil samples heated at $180^{\circ} \mathrm{C}$ for up to $72 \mathrm{hr}$. The AV increased linearly $\left(\mathrm{R}^{2}=0.964\right.$; $\mathrm{p}<0.05)$ corresponding to the increase in heating time. The increase of AV during heating of cooking oil was also reported in other studies (Farida and Siregar, 2006; Abdulkarim et al., 2007). The $\mathrm{C}=\mathrm{O}$ groups shown at $1751.4 \mathrm{~cm}^{-1}$ of FTIR reading might originate from the carboxyl group of FFA measurable by the AV test.

Figure $2 b$ shows the PV from cooking oil samples heated at $180^{\circ} \mathrm{C}$ for up to $72 \mathrm{hr}$. PV was unstable as heating time increased up to $44 \mathrm{hr}$ before started to decrease at a prolonged heating up to $72 \mathrm{hr}$. Other studies have reported the same PV trends of heated cooking oils in which the PV increased during the first stage of frying (Abdulkarim et al., 2007; Chatzilazarou et al., 2006; Faridah et al., 2015; Kaleem et al., 2015; Tsaknis et al., 1998). The formation of unstable hydroperoxide at the initial stage of fat oxidation and then rapid degradation to form secondary oxidation products contributed to this PV profile.

The TBA reactive substance is commonly used as an indicator of lipid oxidation. The method uses the reaction of TBA and malondialdehyde in the glacial acetic acid medium. The higher concentration of malondialdehyde indicates the extent of fat oxidation. Figure $2 c$ shows a significant increase in TBAV of palm oil samples with heating times for up to $44 \mathrm{~min}$. The presence of unsaturated fatty acids in palm oil and the continuous heating process caused the formation of malondialdehyde, which contributed to the increase of TBAV. At a prolonged heating up to $72 \mathrm{hr}$, the TBAV tended to remain constant. The malondialdehyde probably changed gradually under an extended heating process to form more complex secondary oxidation products, such as higher molecular weight compounds that were not detectable when using TBA test (Shahidi et al., 2017).

\section{PLS-OLS Models to Predict AV, PV and TBAV}

Table 2 presents the linear regression models for correlating the percentage of absorbance intensity of significant wavenumbers of FTIR reading with the AV, PV and TBAV. All regression models were insignificant suggesting the FTIR reading at any wavenumbers cannot be directly correlated with the AV and TBAV results. For this reason, the PLSOLS multivariate mathematical models were used to correlate the percentage of absorbance intensity with AV, PV and TBAV.

The PLS-OLS mathematical models in Table 3 were useful for predicting the AV, PV and TBAV by inputting the percentage of absorbance intensity of each dominant wavenumber to the models. The fittest models were based on the significant degree of determination $\left(R^{2}\right)$ that gave p-value $(\operatorname{Pr}>F)$ in the analysis of variance. The FTIR shows the 11 main wavenumbers, namely $721.4,871.8$, 968.3, 1033.9, 1095.6, 1377.2, 1462, 1751.4, 2731.2, 2839.2 and $3005.1 \mathrm{~cm}^{-1}$, were provided by their significant absorbance intensities (Table 2). These wavenumbers represent the existence of functional groups of carbon double bonds (alkenes), esters and aldehydes. Alkene groups are found in many unsaturated fatty acids, while the ester group is negatively correlated with the amount of FFA. A higher number of ester groups indicates the higher fatty acids bound to glycerol. On the other hand, the fewer ester groups show that more hydrolysis reactions occur so that more FFA are produced. The higher amount of aldehyde group reflects the extent of fat oxidation. 
(a)

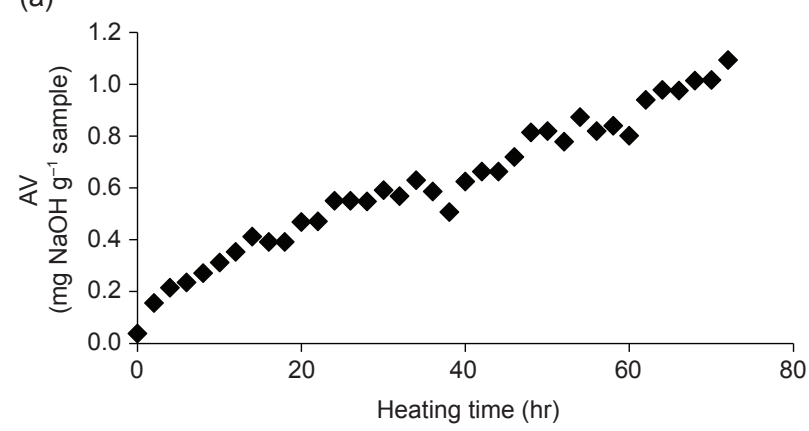

(b)

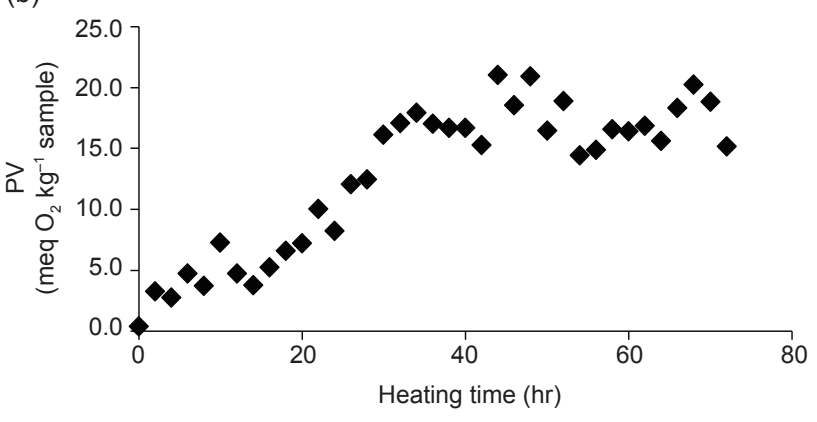

(c)

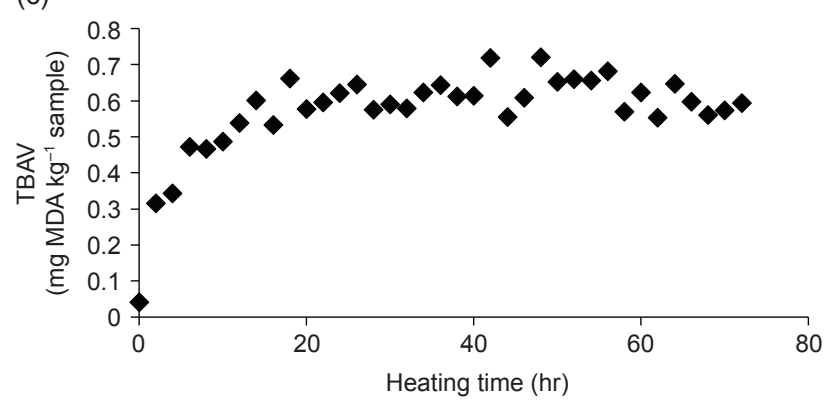

Figure 2. (a) Acid value (AV), (b) peroxide value (PV), and (c) thiobarbituric acid value (TBAV) of palm oil heated at $180^{\circ} \mathrm{C}$ for up to $72 \mathrm{hr}$.

TABLE 2. THE LINEAR REGRESSION MODELS FOR CORRELATING THE PERCENTAGE OF ABSORBANCE INTENSITY OF SIGNIFICANT WAVENUMBERS OF FTIR READING WITH THE AV, PV AND TBAV

\begin{tabular}{ccccccc}
\hline $\begin{array}{c}\text { Wavenumber } \\
\left(\mathbf{c m}^{-\mathbf{1}} \mathbf{n}\right.\end{array}$ & AV & $\mathbf{R}^{\mathbf{2}}$ & $\mathbf{P V}$ & $\mathbf{R}^{\mathbf{2}}$ & TBAV & $\mathbf{R}^{\mathbf{2}}$ \\
\hline 721.4 & $-0.2277 \% \mathrm{IA}+2.8426$ & 0.163 & $-0.0112 \% \mathrm{IA}+2.8463$ & 0.206 & $-0.7735 \% \mathrm{IA}+3.1440$ & 0.401 \\
871.8 & $0.1170 \% \mathrm{IA}+2.6308$ & 0.008 & $-0.0029 \% \mathrm{IA}+2.7398$ & 0.003 & $-0.9612 \% \mathrm{IA}+3.2511$ & 0.113 \\
968.3 & $0.5134 \% \mathrm{IA}+2.3872$ & 0.266 & $0.0138 \% \mathrm{IA}+2.5103$ & 0.107 & $-0.0335 \% \mathrm{IA}+2.7218$ & 0.000 \\
1033.9 & $-0.5085 \% \mathrm{IA}+3.0152$ & 0.051 & $-0.0094 \% \mathrm{IA}+2.8863$ & 0.021 & $-0.6368 \% \mathrm{IA}+3.0660$ & 0.017 \\
1095.6 & $-0.0994 \% \mathrm{IA}+2.7638$ & 0.001 & $-0.0210 \% \mathrm{IA}+2.9716$ & 0.033 & $-1.2293 \% \mathrm{IA}+3.4040$ & 0.046 \\
1377.2 & $0.0968 \% \mathrm{IA}+2.6452$ & 0.025 & $0.0012 \% \mathrm{IA}+2.6874$ & 0.003 & $-0.2007 \% \mathrm{IA}+2.8172$ & 0.032 \\
1462.0 & $0.3464 \% \mathrm{IA}+2.4898$ & 0.013 & $0.0147 \% \mathrm{IA}+2.5152$ & 0.012 & $2.0290 \% \mathrm{IA}+1.5452$ & 0.095 \\
1751.4 & $0.0543 \% \mathrm{IA}+2.6693$ & 0.000 & $0.0074 \% \mathrm{IA}+2.8085$ & 0.003 & $-0.6547 \% \mathrm{IA}+3.0762$ & 0.011 \\
2731.2 & $1.3244 \% \mathrm{IA}+1.8888$ & 0.151 & $0.0399 \% \mathrm{IA}+2.1922$ & 0.072 & $-1.2223 \% \mathrm{IA}+3.4000$ & 0.028 \\
2839.2 & $0.2357 \% \mathrm{IA}+2.5578$ & 0.006 & $0.0148 \% \mathrm{IA}+2.5136$ & 0.012 & $0.5361 \% \mathrm{IA}+2.3969$ & 0.006 \\
3005.1 & $-0.1729 \% \mathrm{IA}+2.8089$ & 0.004 & $-0.0388 \% \mathrm{IA}+3.1994$ & 0.113 & $-2.1883 \% \mathrm{IA}+3.9511$ & 0.147 \\
\hline
\end{tabular}

Note: AV - acid values; PV - peroxide values; TBAV - thiobarbituric acid values; FTIR - Fourier transform infrared.

TABLE 3. PLS-OLS MATHEMATICAL MODELS OF PERCENTAGE OF ABSORBANCE INTENSITY (\% IA) TO PREDICT THE AV, PV AND TBAV OF HEATED PALM OIL

\begin{tabular}{|c|c|c|c|}
\hline Analysis & Multivariate equation models of FTIR measurement & $\mathbf{R}^{2}$ & $\mathbf{P}^{*}$ \\
\hline AV & $\begin{array}{l}0.9880-0.8963 x\left(\% \mathrm{IA}_{721.28}\right)-0.7138 x\left(\% \mathrm{IA}_{871.82}\right)+1.8433 \times\left(\% \mathrm{IA}_{968.27}\right)-0.0123 x\left(\% \mathrm{IA}_{1033.9}\right) \\
+0.0346 x\left(\% \mathrm{IA}_{1095.6}\right)-0.3841 \times\left(\% \mathrm{IA}_{1377.2}\right)-0.0103 \times\left(\% \mathrm{IA}_{1462}\right)+0.0118 \times\left(\% \mathrm{IA}_{1751.4}\right)- \\
0.0478 x\left(\% \mathrm{IA}_{2731.2}\right)+0.0051 \times\left(\% \mathrm{IA}_{2839.2}\right)+0.0319 x\left(\% \mathrm{IA}_{3005.1}\right)\end{array}$ & 0.962 & $<0.0001$ \\
\hline PV & $\begin{array}{l}33.1672-16.1175 \times\left(\% \mathrm{IA}_{721.28}\right)-11.3624 \times\left(\% \mathrm{IA}_{871.82}\right)+29.2246 x\left(\% \mathrm{IA}_{968.27}\right)-0.7629 \times\left(\% \mathrm{IA}_{1033.9}\right) \\
+0.0570 \times\left(\% \mathrm{IA}_{1005.6}\right)-6.3644 \times\left(\% \mathrm{IA}_{1377.2}\right)-0.6087 \times\left(\% \mathrm{IA}_{1462}\right)+0.3081 \times\left(\% \mathrm{IA}_{1751.4}\right)+ \\
1.3272 \times\left(\% \mathrm{IA}_{273.2}\right)+0.1276 \times\left(\% \mathrm{IA}_{2839.2}\right)-3.3650 \times\left(\% \mathrm{IA}_{3005.1}\right)\end{array}$ & 0.857 & $<0.0001$ \\
\hline TBAV & $\begin{array}{l}1.2264-0.8268 x\left(\% \mathrm{IA}_{721.28}\right)-0.2581 \times\left(\% \mathrm{IA}_{871.82}\right)+0.9619 x\left(\% \mathrm{IA}_{968.27}\right)-0.0246 x\left(\% \mathrm{IA}_{1033.9}\right) \\
+0.0090 \times\left(\% \mathrm{IA}_{1095.6}\right)+0.0336 x\left(\% \mathrm{IA}_{1377.2}\right)-0.0128 \times\left(\% \mathrm{IA}_{1462}\right)-0.0284 \times\left(\% \mathrm{IA}_{1751.4}\right)- \\
0.1266 x\left(\% \mathrm{IA}_{2731.2}\right)-0.0031 \times\left(\% \mathrm{IA}_{2839.2}\right)+0.0480 x\left(\% \mathrm{IA}_{3005.1}\right)\end{array}$ & 0.845 & $<0.0001$ \\
\hline
\end{tabular}

Note: *Significantly different at 5\%; AV - acid values; PV - peroxide values; TBAV - thiobarbituric acid values; PLS-OLS - partial least squares-ordinary least squares. 
A significant linear correlation $\left(R^{2}=0.962\right.$; $\mathrm{p}<0.05)$ was shown between $\mathrm{AV}$ and the percentage of absorbance intensity of heated palm oil at $180^{\circ} \mathrm{C}$ for up to $72 \mathrm{hr}$ (Table 3). This mathematical model was only valid for predicting AV under the experimental conditions applied in this study (10 litres of palm oil heated at $180^{\circ} \mathrm{C}$ for up to $72 \mathrm{hr}$ ). The plot of PLSOLS (Figure 3a) shows adjacent values between the predicted and actual AV, suggesting a good prediction of the mathematical model. Similarly, the mathematical model fitted well $\left(R^{2}=0.875 ; \mathrm{p}<0.05\right)$ to predict PV at a heating time up to $72 \mathrm{hr}$ (Figure $36)$. A linear mathematical model for predicting TBAV was valid $\left(R^{2}=0.845 ; p<0.05\right)$ for the heating process up to $58 \mathrm{hr}$ that gave a TBAV of $0.58 \mathrm{mg}$ malondialdehyde $\mathrm{kg}^{-1}$ sample. At prolonged heating times, the model was not accurate for predicting the TBAV (Figure 3c). This finding might result from the yield of volatiles or different polar molecules due to extended oxidation, which is difficult measure using the TBAV method (Aladedunye and Przybylski, 2014).

Table 4 shows the verification results of palm oil heated up to $180^{\circ} \mathrm{C}$ for $24 \mathrm{hr}$. The actual and predicted $\mathrm{AV}, \mathrm{PV}$ and $\mathrm{TBAV}$ show insignificant deviation $(p>0.05)$, indicating the differences in actual and calculated $\mathrm{AV}, \mathrm{PV}$ and TBAV from the OLS models were not significant. Given this result, the mathematical models appear to be useful for predicting the degree of palm oil quality during frying by applying simple and rapid FTIR spectroscopy measurements.

(a)

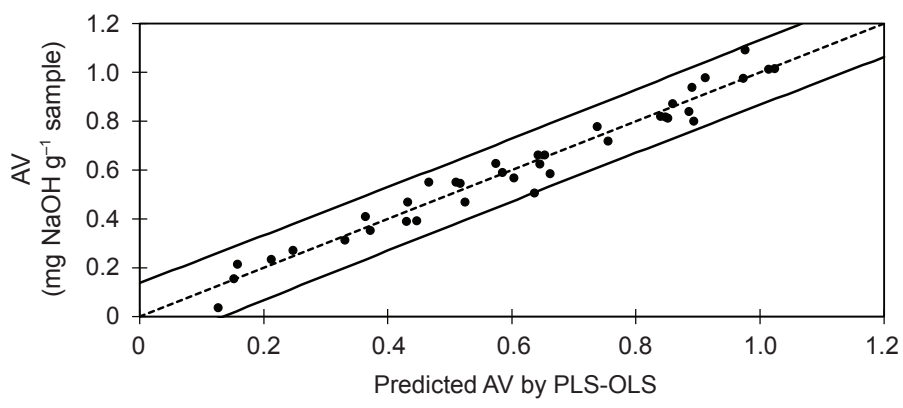

(b)

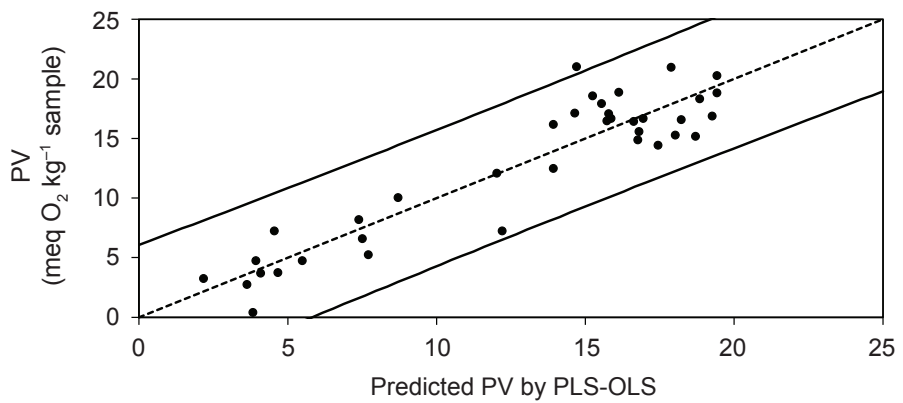

(c)

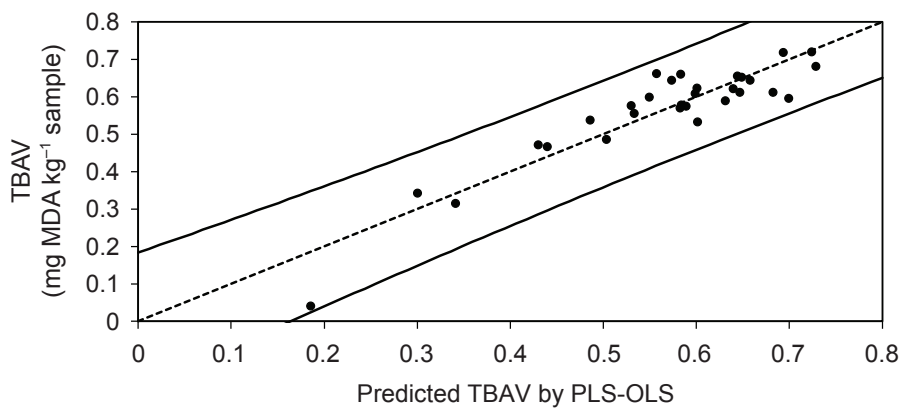

Figure 3. Plots of partial least squares-ordinary least squares (PLS-OLS) predicted values with actual values of palm oil heated at $180^{\circ} \mathrm{C}$. (a) acid value $(A V),(b)$ peroxide value $(P V),(c)$ thiobarbituric acid value (TBAV). Dots show the plots between the predicted and actual values. Lines indicate the ideal curve if $R^{2}=1$.

TABLE 4.VERIFICATION OF COOKING OIL SAMPLE HEATED AT $180^{\circ} \mathrm{C}$ FOR 24 HR USING PAIR T TEST

\begin{tabular}{lccc}
\hline Parameter & Actual value & $\begin{array}{c}\text { Predicted value using } \\
\text { PLS-OLS model }\end{array}$ & $\begin{array}{c}\text { Sig. } \\
\text { (2-tailed) }\end{array}$ \\
\hline Acid value $\left(\mathrm{mg} \mathrm{NaOH} \mathrm{g}^{-1}\right.$ sample) $^{*}$ & 0.625 & 0.600 & 0.148 \\
Peroxide value (meq O $\mathrm{kg}^{-1}$ sample) & 13.034 & 12.706 & 0.228 \\
Thiobarbituric acid value $\left(\mathrm{mg} \mathrm{MDA} \mathrm{kg}^{-1}\right.$ sample) & 0.545 & 0.452 & 0.154 \\
\hline
\end{tabular}

Note: *Not significantly different ( $>0.05)$; PLS-OLS - partial least squares-ordinary least squares. 


\section{CONCLUSION}

FTIR spectroscopy can be applied as an alternative to conventional methods of acid, peroxide and TBA value determinations for monitoring the quality changes of cooking oil during a long period of frying.

\section{ACKNOWLEDGEMENT}

The authors are very thankful to the Food Analysis Laboratory of Department of Food Science and Technology, Bogor Agricultural University (IPB University) Indonesia for the technical and financial supports of this research.

\section{REFERENCES}

Abdi, H (2003). Partial least squares (PLS) regression. Encycl Soc. Sci. Res. Methods (LewsBeck, M; Bryman, A and Futing, T eds.). p. 792-795.

Abdulkadir, I; Uba, S; Salihu, A and Almustapham, M N (2016). A rapid method of crude oil analysis using FTIR spectroscopy. Nig. J. Basic Appl. Sci., 24(1): 47-55.

Abdulkarim, S M; Long, K; Lai, O M; Muhammad, S K S and Ghazali, H (2007). Frying quality and stability of high-oleic Moringa oleifera seed oil in comparison with another vegetable oils. Food Chem., 105(4): 1382-1389.

Aladedunye, F and Przybylski, R (2014). Performance of palm olein and modified rapeseed, sunflower, soybean oils in intermittent deep-frying. Eur. J. Lipid Sci. Technol., 116(2): 144-152.

Al-Degs, Y S and Al-Ghouti, M S N (2011). Determination of frying quality of vegetable oils used for preparing falafel using infrared spectroscopy and multivariate calibration. Food Anal. Methods, 4(4): 540-549.

Ang, Y H; Yew, M Y; Abas W; Lai, M F; Wang, Y, Lai, O M and Tan, C P (2019). Rapid assessment of total MCPD esters in palm-based cooking oil using ATR-FTIR application and chemometric analysis. Talanta, 198(5): 215-223. DOI: 10.1016/j.talanta.2019.01. 111.

AOAC (1984). Official Methods of Analysis. Association of Official Analytical Chemistry. Washington DC, USA.
Bhardwaj, S; Passi, S; Misra, A; Pant, K; Anwar, K; Pandey, R and Kardam, V (2016). Effect of heating / reheating of fats / oils, as used by Asian Indians on trans fatty acid formation. Food Chem., 212: 663-700. DOI: 10.1016/j.foodchem.2016.06.021.

Bhuiyan, M T H; Khan M; Rahman, $\mathrm{A}$ and Chowdhury, U C (2016). Effect of reheating on thermophysical properties of edible oil at high temperature. Int. J. Adv. Res. Phys. Sci., 3(2): 30-34.

Chatzilazarou, A; Gortzi, O; Lalas, S; Zoidis, E and Tsaknis, J (2006). Physicochemical changes of olive oil and selected vegetable oils during frying. J. Food Lipids, 13(11): 27-35.

Che Man, Y B and Setiowaty, G (1999a). Application of fourier transform infrared spectroscopy to determine free fatty acid contents in palm olein. Food Chem., 66(1): 109-114.

Che Man, Y B and Setiowaty, G (1999b). Multivariate calibration of fourier transform infrared spectra in determining iodine value of palm oil products. Food Chem., 67(2): 193-198. DOI: 10.1016/S03088146(99)00102-8.

Che Man, Y B; Marina A M; Abdulrohman, H and Al-Kahtani, O N (2014). A fourier transform infrared spectroscopy method for analysis of palm oil adulterated with lard in pre-fried french fries. Int. J. Food Prop., 17(2): 354-362.

Dana, D and Saguy, I (2001). Frying of nutritious food: Obstacles and feasibility. Food Sci. Technol. Res., 7(4): 265-279. DOI: 10.3136/fstr.7.265.

Edem, D (2002). Palm oil: Biochemical, physiological, nutritional, hematological and toxicological aspects - A review. Plant Foods Hum. Nutr., 57: 319-341.

Farahani, H A; Rahiminezhad, A; Same, L and Immannezhad, K (2010). A comparison of partial least squares (PLS) and ordinary least squares (OLS) regressions in predicting of couples mental health based on their communicational patterns. Procedia - Soc. Behav. Sci., 5: 1459-1463.

Farida, Y and Siregar, I (2006). Pengaruh pemanasan berulang terhadap sifat fisikokimia dan kandungan asam palmitat pada minyak goreng. J. Ilmu Kefarmasian Indonesia, 4(2): 83-91.

Faridah, D N; Lioe, H N; Palupi, N S and Kahfi, J (2015). Detection of FFA and PV values using FTIR for quality measurement in palm oil frying activitie. J. Oil Palm Res., 27(2): 156-167. 
Frankel, E (1987). Secondary products of lipid oxidation. Chem. Phys. Lipids, 44(2-4): 73-85.

Gharby, S; Hicham, H; Boulbaroud, S; Bouzoubaâ Z; El Madani, N; Chafchaouni, I and Charrouf, Z (2014). The stability of vegetable oils (sunflower, rapeseed and palm) sold on the Moroccan market at high temperature. Int. J. Chem. Biochem. Sci., 5: 47-54.

Guillen, M D and Cabo, N (1997). Infrared spectroscopy in the study of edible oils and fats. J. Sci. Food Agric., 75: 1-11.

Höskuldsson, A (1998). PLS regression methods. J. Chemometrics, 2(3): 211-228.

Jaarin, K and Kamisah, Y (2012). Repeatedly heated vegetable oils and lipid peroxidation. Lipid Peroxidation (Catala, A ed.). p. 211-228. DOI: 10.5772 / 46076.

Kalapathy, U and Proctor, A (2000). A new method for free fatty acid reduction in frying oil using silicate films produced from rice hull ash. J. Amer. Oil Chem. Soc., 77(6): 593-598.

Kaleem, S; Aziz, S; Iqtedar, M; Abdullah, R; Aftab, M; Rashid, F; Shakoori, F R and Naz, S (2015). Investigating changes and effect of peroxide values in cooking oils subject to light and heat. Fuuast J. Biol., 5(2): 191-196.

Li, Y (2010). A comparison study of principle component regression, partial least squares regression, and ridge regression with application to FTIR data. Ph.D thesis, Uppsala University.

Lim, S Y; Mutalib, M S A; Khaza'ai, H and Chang, S (2018). Detection of fresh palm oil adulteration with recycled cooking oil using fatty acid composition and FTIR spectral analysis. Int. J. Food Prop., 21(1):2428-2451. DOI: 10.1080 / 10942912.2018. 1522332.

Mancini, A; Imperlini, E; Nigro, E; Montagnese, C; Daniele, A; Orrù, S and Buono, P (2018). Biological and nutritional properties of palm oil and palmitic acid: Effects on health. Molecules, 20(9): 1733917361. DOI:10.3390 / molecules200917339.

Martín-Ramos, P; Maria, T M R; Correa-Guimaraes, A; Carrión-Prieto, P; Hernández-Navarro, S and Martín-Gil, J (2018). Crude and refined oils from Elaeis guineensis: Facile characterization by FTIR and thermal analysis techniques. Int. J. Food Prop., 20(53): S2739-2749. DOI: 10.1080/10942912.2017. 1372470.
Mba, O I; Dumont, M J and Ngadi, M (2015). Palm oil: Processing, characterization and utilization in the food industry - A review. Food Biosci., 10(1): 2641. DOI: $10.1016 /$ j.fbio.2015.01.003.

Rohman, A and Che Man, Y (2010). Fourier transform infrared (FTIR) spectroscopy for analysis of extra virgin olive oil adulterated with palm oil. Food Res. Int., 43(3): 886-892.

Rohman, A; Wibowo, D; Sudjadi; Lukitaningsih, E and Rosman, A (2015). Use of fourier transform infrared spectroscopy in combination with partial least square for authentication of black seed oil. Int. J. Food Prop., 18(4): 775-784.

Setiowaty, G and Che Man, Y (2003). A rapid Fourier transform infrared spectroscopic method for the determination of 2-TBARS in palm olein. Food Chem., 81(1): 147-154. DOI: 10.1016/S03088146(02)00396-5.

Shahidi, F; Wang, J and Wanasundara, U (2017). Methods for measuring oxidative rancidity in fats and oils. Food Lipids: Chemistry, Nutrition and Biotechnology (Akoh, C C and Min, D eds.). Second edition. CRC Press. p. 519-542.

SNI (1998). Cooking Oil SNI 01-3555-1998. National Standardization Agency of Indonesia.

Song, J; Park, P; Jung, J; Lee, C; Gim, S Y; Ka, H J; Yi, B; Kim, M; Kim, C and Lee, J (2015). Analysis of trans fat in edible oils with cooking process. Toxicol Res., 31(3): 307-312. DOI: 10.5487/TR.2015.31. 3.307.

Tarladgis, B G; Pearson, A M and Dugan, L (1962). The chemistry of the 2-thiobarbituric acid test for the determination of oxidative rancidity in foods. J. Amer. Oil Chem. Soc., 39(1): 34-39. DOI: $10.1007 /$ BF02633347.

Tsaknis, J; Lalas, S; Gergis, V; Dourtoglou, V and Spiliotis, V (1998). Quality changes of Moringa oleifera, variety of blantyre seed oil during frying. La Riv Ital Sostanze Grasse, 75(4): 181-190. DOI: 10.3989/gya.2002.v53.i2.305.

Vlachos, N; Skopelitis, Y; Psaroudaki, M; Konstantinidou, V; Chatzilazarou, A and Tegou, E (2006). Application of fourier transform infrared spectroscopy to edible oils. Anal. Chim. Acta., 573574: 459-465.

Wong, Y H; Goh, K M; Abas, F; Maulidiani M; Nyam, K L; Nehdi, I A; Sbihi, H M; Gewik, M $\mathrm{M}$ and Tan, C P (2019). Rapid quantification 
of 3-monochloropropane-1,2-diol in deep-fat frying using palm olein: Using ATR-FTIR and chemometrics. LWT. 100: 404-408. DOI: $10.1016 /$ j. lwt.2018.10.088.
Wrolstad, R E; Acree, T E; Decker, E A; Penner, M H; Reid, D S; Schwartz, S J; Shoemaker, C F; Smith, D $\mathrm{M}$ and Sporns, P (2000). Handbook of Food Analytical Chemistry. John Wiley and Sons, Inc. New Jersey. 